\title{
The effect of hepatitis $C$ virologic clearance on cardiovascular disease biomarker lipoprotein-associated phospholipase A2 and its relation to serum lipids
}

Amira Isaac ${ }^{1}$, Basant Elmarashly ${ }^{1 *}$ D, Kadry El Saeed ${ }^{1}$, Rasha Samir Mohamed ${ }^{1}$, Shereen Abdelmonem Ibrahim² and Eslam Safwat ${ }^{1}$

\begin{abstract}
Background: Chronic hepatitis C virus (HCV) infection has been linked to cardiovascular disease (CVD). However, CVD risk prediction in chronic HCV-infected patients is problematic as the prevalence of different cardiac biomarkers in these patients is currently unknown. Serum lipids, which are routinely used in traditional CVD risk scores, may underestimate CVD risk in these patients, while non-hepatically produced biomarkers, including lipoprotein-associated phospholipase A2 (Lp-PLA2), may better reflect CVD risk. In this study, we aimed to evaluate the effect of sustained virologic response (SVR) on CVD risk, predicted by Lp-PLA2 mass in comparison with serum lipid levels.

Results: Ninety chronic HCV-infected patients were enrolled in this study. Serum Lp-PLA2 mass was measured before and after HCV treatment via direct-acting antivirals and compared with the changes in serum lipids and Framingham risk score (FRS). The Lp-PLA2 level was categorized into high ( $>235 \mathrm{ng} / \mathrm{ml}$ ) or low predicted CVD risk ( $\leq 235 \mathrm{ng} / \mathrm{ml}$ ). Mean Lp-PLA2 mass significantly decreased from $322.37 \pm 79.15 \mathrm{ng} / \mathrm{ml}$ to $263.79 \pm 51.804 \mathrm{ng} / \mathrm{ml}$ with SVR, and the number of high-risk patients significantly dropped from 82.22 to $60 \%$ after treatment. Total cholesterol, low-density lipoprotein, and high-density lipoprotein levels were low/optimal at baseline $(170 \pm 40.34 \mathrm{mg} / \mathrm{dl}, 71.98 \pm 24.12 \mathrm{mg} / \mathrm{dl}$, and $48.43 \pm 6.79 \mathrm{mg} / \mathrm{dl})$ and significantly increased with SVR $(195.66 \pm 55.68 \mathrm{mg} / \mathrm{dl}, 103.24 \pm 46.57 \mathrm{mg} / \mathrm{dl}$, and $53.91 \pm$ $8.67 \mathrm{mg} / \mathrm{dl}$ ). According to FRS, only $30 \%$ of patients were moderate/high risk at baseline and insignificantly declined to 28.89\% post-treatment.
\end{abstract}

Conclusion: Lp-PLA2 may be a better predictor of CVD risk in chronic HCV-infected patients. Furthermore, SVR may reduce hepatic inflammation and consequently CVD risk.

Keywords: Hepatitis C, Cardiovascular disease, Lipoprotein-associated phospholipase A2, Serum lipids

\section{Background}

Hepatitis $\mathrm{C}$ virus (HCV) is one of the leading causes of liver cell failure and hepatocellular carcinoma (HCC). The pathological sequelae of HCV infection are not restricted to the liver but prevail in extra-hepatic tissues and organs, causing numerous $\mathrm{HCV}$-associated co-

\footnotetext{
* Correspondence: b_elmarashly@med.asu.edu.eg

'Department of Internal Medicine, Gastroenterology and Hepatology Unit,

Faculty of Medicine, Ain Shams University, Cairo 11566, Egypt

Full list of author information is available at the end of the article
}

morbidities that significantly increase morbidity and mortality, diminishing health-related quality of life [1]. $\mathrm{HCV}$ infection provokes fatty liver infiltration, insulin resistance (IR), type 2 diabetes mellitus (DM), and atherosclerosis [2], which are known complications of the metabolic syndrome, despite a paradoxically "protective" serum lipid profile characterized by optimal or low lowdensity lipoprotein (LDL) and total cholesterol levels [3]. The virus exerts these metabolic changes through its ability to affect hepatic lipid metabolism, interfere with 
insulin signaling, and directly infect the arterial wall causing chronic endothelial damage and systemic inflammation [2]. The development of DAAs has markedly improved treatment outcomes with SVR rates that could reach $90 \%$ or more [4]. HCV clearance has been shown to correct metabolic derangements such as IR and the consequences of direct infection of endothelial cells and monocytes [5]. However, an increase in serum cholesterol and LDL may be observed potentiating early atherosclerotic lesions and necessitating lipid-lowering therapy [6].

There are numerous biomarkers that enable risk stratification and consequently decision-making regarding the management of CVD. They can be grouped based on disease specificity, such as biomarkers of heart failure (brain natriuretic peptide and atrial natriuretic peptide) and of atherosclerotic coronary disease (troponin T or I, creatinine phosphokinase-MB), or they can be grouped according to the pathologic process they mediate, such as inflammation (high-sensitivity C-reactive protein [hsCRP], interleukin 6, fibrinogen, tumor necrosis factor-alpha), oxidative stress (isoprostanes), and metabolic biomarkers (lipoprotein (a), LDL, Lp-PLA2) [7].

Lp-PLA2, also known as platelet-activating factor acetylhydrolase, is mainly produced by macrophages and foam cells within atherosclerotic plaques, particularly in sites where leucocyte influx, cellular necrosis, and calcification are profound [8]. It promotes the pathogenesis of atherosclerosis through hydrolysis of oxidized phospholipids on modified LDL particles within the arterial intima [8]. Hence, the concentration of Lp-PLA2 and its by-product, lysophosphatidylcholine, in the coronary circulation reflects atheromatous plaque formation and a high risk of rupture [9]. Lp-PLA2 is characterized by its low biologic variability and high specificity for vascular inflammation, rather than systemic inflammation, and has a direct correlation with plaque inflammation making it a valuable biomarker reflecting CVD risk and a potential therapeutic target [10]. Based on several epidemiologic studies, an LpPLA2 level > $235 \mathrm{ng} / \mathrm{ml}$ in healthy populations was found to signify a high risk for CVD [11]. Our aims were to measure serum lipid levels (hepatic CVD biomarkers) and Lp-PLA2 concentration (non-hepatic CVD biomarker) in chronic $\mathrm{HCV}$-infected patients and explore the potential benefit of $\mathrm{HCV}$ treatment on cardiovascular outcomes, hypothesizing that SVR would be associated with a favorable reduction in the non-hepatic CVD biomarker and consequently CVD risk.

\section{Methods}

This study was conducted on 90 patients with chronic $\mathrm{HCV}$ infection who were eligible for antiviral treatment with DAAs, agreeable to regular follow-up. They were recruited from the National Committee for Control of
Viral Hepatitis $(\mathrm{NCCVH})$ regional center in Ain Shams University hospital during the period from May 2019 to April 2020, after approval of the Ain Shams University ethics committee was granted, and informed consents were taken from all patients.

All participants included in this study were 30 years or older, had no underlying CVD, had chronic HCV infection without concomitant hepatitis $\mathrm{B}$ virus (HBV) or human immunodeficiency virus (HIV) infection, had not previously undergone liver transplantation, had no history of HCC, had normal serum creatinine levels, were Child A or Child B7 according to Child-Pugh classification, were treatment-naïve, and were defined as "easy to treat" or "difficult to treat" (any of these criteria: total serum bilirubin $\geq 1.2 \mathrm{mg} / \mathrm{dl}$, serum albumin $\leq 3.5 \mathrm{~g} / \mathrm{dl}$, INR $\geq 1.2$, platelet count $<150,000 / \mathrm{mm}^{3}$ ) as per the Egyptian NCCVH protocol, and accordingly administered an appropriate, personally tailored, DAA regimen for 3 months during the course of this study [12, 13]. All female patients were neither pregnant nor lactating throughout the course of this study.

For all patients, relevant history taking and clinical examination were conducted, and the following laboratory tests analyzed, using commercially available kits: alanine transaminase (ALT), aspartate transaminase (AST), serum albumin level, serum bilirubin level, international normalized ratio (INR), serum alpha-fetoprotein (AFP), complete blood count (CBC), quantitative $\mathrm{HCV}$ RNA assay, hepatitis B surface antigen ( $\mathrm{HBsAg}$ ) and HIV antibody, serum creatinine level and creatinine clearance, fasting blood glucose (FBG) and hemoglobin A1C (HbA1c), and lipid profile including LDL, HDL, and total cholesterol. Lp-PLA2 mass was measured using RayBio $^{\circ}$ Human Lp-PLA2 ELISA Kit. Twelve weeks after the end of treatment, HCV RNA was assessed to determine SVR, and Lp-PLA2 mass was measured and compared with serum lipids.

Furthermore, the Framingham CVD risk score (2008) was calculated for all patients before and after treatment and compared to the Lp-PLA2 level in terms of CVD risk predictability. Framingham risk score is an algorithm used to estimate the 10-year CVD risk of an individual, and it comprises six coronary risk factors, including sex, age, smoking history, systolic blood pressure, total cholesterol, and HDL levels. Individuals with low risk have $10 \%$ or less global CVD risk at 10 years, with intermediate risk $10-20 \%$, and with high risk $20 \%$ or more [14].

Lastly, abdominal ultrasound and transient elastography were done for all patients before and after treatment to identify cirrhosis.

Lp-PLA2 mass assay was done by means of RayBio ${ }^{\circledR} \mathrm{Hu}-$ man Lp-PLA2 ELISA Kit, which is an in vitro enzymelinked immunosorbent (ELISA) assay that employs an 
antibody specific for human Lp-PLA2 coated on a 96-well plate. Standards and samples were pipetted into the wells, and Lp-PLA2 present in a sample was bound to the wells by the immobilized antibody. The wells were washed, and biotinylated anti-human Lp-PLA2 antibody was added. After washing away the unbound biotinylated antibody, horseradish peroxidase (HRP)-conjugated streptavidin was pipetted to the wells. The wells were again washed, a tetramethylbenzidine (TMB) substrate solution was added, and color developed in proportion to the amount of LP-PLA2 bound. The Stop Solution changed the color from blue to yellow, and the intensity of the color was measured at 450 $\mathrm{nm}$. The mean absorbance for standards and samples was calculated, and the average zero standard optical density was subtracted. A standard curve was plotted on log-log graph paper, with standard concentration on the $\mathrm{x}$-axis and absorbance on the y-axis. A best-fit straight line through the standard points was drawn. The minimum detectable dose of human Lp-PLA2 (the analyte concentration resulting in an absorbance that is 2 SD higher than that of the blank) was determined to be $8.1 \mathrm{ng} / \mathrm{ml}$.

\section{Statistical analysis}

The collected data were coded, tabulated, and statistically analyzed using IBM SPSS statistics (Statistical Package for Social Sciences) software version 20. Quantitative data were expressed as mean \pm SD (standard deviation) for normally distributed data. Qualitative data were presented as numbers and percentages.

In quantitative data, Student's t-test was used to compare two independent groups with normally distributed data and paired t-test in cases of two dependent groups with normally distributed data. Analysis of variance (ANOVA) (F) test was used to compare between more than two independent groups with normally distributed data, followed by post hoc analysis to compare between every two groups. In qualitative data, inferential analyses for independent variables were done using the chisquare $\left(\mathrm{X}^{2}\right)$ test for differences between proportions. Correlations were done using the Pearson correlation coefficient test $(r)$. The receiver operating characteristic (ROC) curve was constructed to obtain the most sensitive and specific cut-off values for different parameters to discriminate patients with high CVD risk from those with low CVD risk. The level of significance was determined by the $\mathrm{p}$-value where $p<0.05$ is significant, $<0.01$ is highly significant, and otherwise is insignificant.

\section{Results}

Total studied patients comprised 55 males (61.11\%) and 35 females (38.89\%), with ages ranging from 30 to 68 years old (mean $46.88 \pm 10.61$ years). Per abdominal ultrasound and transient elastography, 22 patients were found to have liver cirrhosis. Amongst cirrhotic patients,
9/22 (40.91\%) were Child A5, 12/22 (54.55\%) were Child A6, and 1/22 (4.55\%) was Child B7, as per the ChildPugh score. "Easy to treat" patients (50\%), as per NCCV $\mathrm{H}$ guidelines, were given sofosbuvir (SOF) and daclatasvir (DCV) while "difficult to treat" patients (50\%) were administered SOF, DCV, and ribavirin (RBV). Twelve weeks after the end of treatment, SVR was observed in $86 / 90$ patients $(96.6 \%)$. Four of 90 patients $(4.4 \%)$ had not achieved SVR, with no statistical significance between their pre-treatment and post-treatment $\mathrm{HCV}$ RNA levels $(p=0.068)$.

Baseline characteristics of the study cohort regarding demographic data, the prevalence of different CVD risk factors, Child score, and fibrosis stage are summarized in Table 1.

A comparison between cirrhotic and non-cirrhotic patients regarding baseline biochemical parameters and FRS is highlighted in Table 2 and demonstrates that most of the studied parameters were statistically significant between both groups, except AST, hemoglobin level, Lp-PLA2 mass, and Framingham risk score $(p>$ 0.05). Notably, total cholesterol level, LDL, and HDL levels were significantly lower in cirrhotic patients as compared to non-cirrhotic patients $(p<0.001)$. There was no statistically significant difference in abdominal ultrasound findings $(p=0.84)$, liver stiffness score $(p=$ 0.596 ), and Child-Pugh score of cirrhotic patients ( $p=$ 0.181 ) after treatment as compared to baseline.

A statistically significant increase in serum total cholesterol, LDL, and HDL was observed in patients who achieved SVR $(p<0.001) 12$ weeks after the end of treatment, while no or insignificant change was observed in non-SVR patients $(p=0.391, p=0.115, p=$ 0.444) (Tables 3 and 4).

Furthermore, our study demonstrated a significant decrease in Lp-PLA2 concentration after DAA therapy, in patients who experienced SVR $(263.79 \pm 51.804 \mathrm{ng} / \mathrm{ml}$ vs. $322.37 \pm 79.15 \mathrm{ng} / \mathrm{ml})(p<0.001)$. On the contrary, patients who did not achieve SVR experienced a nonsignificant rise in post-treatment Lp-PLA2 concentration $(392.25 \pm 88.733 \mathrm{ng} / \mathrm{ml}$ vs. $370 \pm 98.668 \mathrm{ng} / \mathrm{ml})(p=$ 0.198) (Tables 3 and 4).

The Lp-PLA2 level was analyzed as a continuous variable and categorized into high $(>235 \mathrm{ng} / \mathrm{ml}$ ) or low predicted CVD risk $(\leq 235 \mathrm{ng} / \mathrm{ml})$. There is a significant decline in the number of patients classified as high risk, after treatment with DAAs, from $74 / 90(82.22 \%)$ to $54 / 90$ (60\%), with a consequent rise in the number of low-risk patients from $16 / 90(17.78 \%)$ to $36 / 90(40 \%)$ post-treatment $(p=0.002)$. Notably, no statistically significant difference in baseline Lp-PLA2 concentration has been shown between cirrhotic and non-cirrhotic patients $(p=0.463)$ (Table 2).

Framingham risk score, designed to predict 10-year CVD risk, was calculated for all patients before and after 
Table 1 Baseline characteristics of all studied patients

\begin{tabular}{|c|c|c|}
\hline \multicolumn{3}{|l|}{ Descriptive data } \\
\hline \multicolumn{2}{|c|}{ Age (years), mean \pm SD (range) } & $46.878 \pm 10.605(30-68)$ \\
\hline \multicolumn{2}{|c|}{ BMI $\left(\mathbf{k g} / \mathbf{m}^{2}\right)$, mean \pm SD (range) } & $26.232 \pm 2.140(21-31)$ \\
\hline \multirow[t]{2}{*}{ Gender, n (\%) } & Male & $55(61.11 \%)$ \\
\hline & Female & $35(38.89 \%)$ \\
\hline \multirow[t]{2}{*}{ Smoking, $\mathrm{n}(\%)$} & Smoker & $18(20 \%)$ \\
\hline & Non-smoker & $72(80 \%)$ \\
\hline \multirow[t]{2}{*}{ Hypertension, n (\%) } & Hypertensive & $15(16.67 \%)$ \\
\hline & Normotensive & 75 (83.33\%) \\
\hline \multirow{3}{*}{$\begin{array}{l}\text { Diabetes mellitus, } n \\
(\%)\end{array}$} & Diabetic & $7(7.78 \%)$ \\
\hline & Pre-diabetic & $13(14.44 \%)$ \\
\hline & Non-diabetic & $70(77.78 \%)$ \\
\hline \multicolumn{2}{|c|}{ FBG $(\mathbf{m g} / \mathbf{d l})$, mean \pm SD (range) } & $89.989 \pm 15.786(66-135)$ \\
\hline \multicolumn{2}{|c|}{ HbA1c (\%), mean \pm SD (range) } & $5.420 \pm 0.609(4.1-7)$ \\
\hline \multirow[t]{3}{*}{ Child score, n (\%) } & A5 & $\begin{array}{l}9(40.91 \%) \\
9(45 \%)\end{array}$ \\
\hline & A6 & $\begin{array}{l}12(54.55 \%) \\
10(50 \%)\end{array}$ \\
\hline & B7 & $\begin{array}{l}1(4.55 \%) \\
1(5 \%)\end{array}$ \\
\hline \multirow[t]{5}{*}{ Fibrosis stage, $\mathrm{n}(\%)$} & Fo & $16(17.78 \%)$ \\
\hline & F1 & $39(43.33 \%)$ \\
\hline & F2 & $10(11.11 \%)$ \\
\hline & F3 & $3(3.33 \%)$ \\
\hline & $\mathrm{F} 4$ & $22(24.44 \%)$ \\
\hline \multirow[t]{2}{*}{ DAA regimen, $\mathrm{n}(\%)$} & SOF/DCV & $45(50 \%)$ \\
\hline & SOF/DCV/RBV & $45(50 \%)$ \\
\hline \multicolumn{2}{|c|}{ HCV RNA (IU/ml), median (IQR) } & $\begin{array}{l}2,253,000(573,662.25-4,000, \\
000)\end{array}$ \\
\hline
\end{tabular}

Abbreviations: $S D$, standard deviation; $n$, number; $B M I$, body mass index; $D A A$, direct-acting antiviral; $S O F$, sofosbuvir; $D C V$, daclatasvir; $R B V$, ribavirin; $F B G$, fasting blood glucose; $H C V$, hepatitis $C$ virus; $R N A$, ribonucleic acid; $I Q R$, interquartile range

HCV treatment, and patients were accordingly stratified into low-, moderate-, and high-risk groups. At baseline, $14 / 90(15.56 \%)$ were classified as high risk, 13/90 (14.44\%) as moderate risk, and 63/90 (70\%) as low risk. There was no significant difference in calculated risk scores and risk stratification into each group after treatment as compared to baseline $(p=0.976)$.

Regarding different CVD risk factors, gender had a statistically significant impact on Lp-PLA2 level where men had significantly higher levels than women $(p<0.001)$. Also, significantly higher levels were noted amongst hypertensive patients, diabetic patients, and smokers ( $p$ $<0.001,0.008,<0.001$, respectively). Using post hoc analysis, a significant difference in Lp-PLA2 levels between diabetic and non-diabetic patients $(p=0.015)$ was noted. In addition, "difficult to treat" patients administered SOF/DCV/RBV were found to have significantly higher levels of Lp-PLA2 as opposed to "easy to treat patients" given SOF/DCV ( $p=0.006)$ (Table 5).

Pre-treatment Lp-PLA2 concentration showed a statistically significant positive correlation with age, BMI, FBG, HbA1c, and Framingham score and a statistically significant negative correlation with serum albumin and platelet count. In addition, post-treatment Lp-PLA2 level shows a significant positive correlation with age, BMI, FBG, HbA1c, AST, and both liver stiffness score and Framingham risk score. On the other hand, there is a significant negative correlation with HDL, serum albumin, and platelet count (Table 6).

Finally, our study demonstrated the diagnostic performance of the best cut-off values of baseline AST, ALT, serum albumin, platelet count, and liver stiffness score in differentiating between high and low CVD risk, as defined by an Lp-PLA2 cut-off value of $>235 \mathrm{ng} / \mathrm{ml}$. At a cut-off value of $>29 \mathrm{IU} / \mathrm{l}$ for AST, the sensitivity was $78.38 \%$ and specificity $43.75 \%$ with an accuracy of $57.5 \%$, and at a cut-off value of $>28$ IU/l for ALT, the sensitivity was slightly higher $(82.43 \%)$, yet the specificity was much lower (31.25\%) with slightly less accuracy of $52 \%$. A liver stiffness score of $>6.3 \mathrm{kPa}$ provides a relatively better specificity of $75 \%$ and accuracy of $62.2 \%$. At a cut-off value of $\leq 261,000 / \mu$ l for platelet count, the sensitivity was $79.73 \%$ and specificity $56.25 \%$ with an accuracy of $71.8 \%$. Last but not least, at a cut-off value of $\leq 3.7$ $\mathrm{g} / \mathrm{dl}$ for serum albumin, the sensitivity in discriminating high from low CVD risk was the lowest (37.84\%) amongst the five parameters analyzed, yet specificity was the highest (93.75\%) with an accuracy of $63.7 \%$ (Fig. 1).

\section{Discussion}

HCV infection increases CVD risk through several mechanisms, including insulin resistance, hepatic steatosis, and increased chronic inflammation and immune activation [15].

There are countless risk score calculators and charts that aim to predict 10-year CVD risk in the general population. However, serum lipids, which are incorporated in most CVD risk scores, including the Framingham risk score, are reduced in the setting of chronic liver disease and may therefore underestimate CVD risk in infected persons [16]. This highlights the need for alternative means to estimate CVD risk in chronic HCVinfected patients and the validation of non-hepatically produced CVD biomarkers for this purpose.

Lipoprotein-associated phospholipase A2 (Lp-PLA2) is a novel inflammatory marker that has been found to be a CVD risk marker independent of traditional risk factors, including LDL and hsCRP [17]. It is characterized by high vascular endothelial specificity and low biovariability [18].

Regarding changes in serum lipids, this study illustrates low or optimal levels of baseline total cholesterol, LDL, and HDL with a statistically significant increase after SVR 
Table 2 Comparison between cirrhotic and non-cirrhotic patients regarding baseline patients' age, biochemical parameters, and Framingham risk score

\begin{tabular}{|c|c|c|c|c|}
\hline \multirow[t]{2}{*}{ Baseline parameter } & \multirow{2}{*}{$\begin{array}{l}\text { Cirrhotic patients } \\
(n=22)\end{array}$} & \multirow{2}{*}{$\begin{array}{l}\text { Non-cirrhotic } \\
\text { patients }(n=68)\end{array}$} & \multicolumn{2}{|c|}{ Student's t-test } \\
\hline & & & $\mathbf{t}$ & $\mathbf{p}$ \\
\hline Age (years) & $51.045 \pm 10.781$ & $45.529 \pm 10.267$ & 2.164 & 0.033 \\
\hline AST (IU/I) & $55.955 \pm 35.77$ & $45.971 \pm 24.985$ & 1.457 & 0.149 \\
\hline ALT (IU/I) & $70.909 \pm 50.675$ & $48.824 \pm 33.663$ & 2.344 & 0.021 \\
\hline Albumin (g/dl) & $3.653 \pm 0.487$ & $4.05 \pm 0.393$ & -3.881 & $<0.001$ \\
\hline Total bilirubin (mg/dl) & $0.94 \pm 0.524$ & $0.698 \pm 0.308$ & 2.663 & 0.009 \\
\hline Direct bilirubin (mg/dl) & $0.464 \pm 0.233$ & $0.349 \pm 0.234$ & 2.012 & 0.047 \\
\hline INR & $1.165 \pm 0.156$ & $1.087 \pm 0.114$ & 2.546 & 0.013 \\
\hline Hemoglobin (g/dl) & $13.136 \pm 1.593$ & $13.557 \pm 1.548$ & -1.101 & 0.274 \\
\hline Total leucocyte count $\left(10^{3} / \mu \mathrm{l}\right)$ & $5.695 \pm 1.861$ & $7.150 \pm 2.487$ & -2.520 & 0.014 \\
\hline Platelet count $\left(10^{3} / \mu \mathrm{l}\right)$ & $159.727 \pm 71.748$ & $219.044 \pm 80.611$ & -3.077 & 0.003 \\
\hline LDL (mg/dl) & $39.001 \pm 7.528$ & $80.397 \pm 19.489$ & -9.701 & $<0.001$ \\
\hline Total cholesterol (mg/dl) & $122.409 \pm 29.156$ & $182.103 \pm 33.774$ & -7.436 & $<0.001$ \\
\hline $\mathrm{HDL}(\mathrm{mg} / \mathrm{dl})$ & $40.136 \pm 5.375$ & $50.544 \pm 5.462$ & -7.798 & $<0.001$ \\
\hline Lp-PLA2 (ng/ml) & $335.455 \pm 74.345$ & $320.941 \pm 82.023$ & 0.737 & 0.463 \\
\hline Framingham risk score & $10.323 \pm 9.921$ & $8.175 \pm 8.205$ & 1.013 & 0.314 \\
\hline
\end{tabular}

Abbreviations: $n$, number; $A S T$, aspartate transaminase; $A L T$, alanine transaminase; $I N R$, international normalized ratio; $L D L$, low-density lipoprotein; $H D L$, highdensity lipoprotein; $L p-P L A 2$, lipoprotein-associated phospholipase A2

achievement $(p<0.001)$, regardless of fibrosis, compared to non-SVR patients, who experienced an insignificant change in their lipid profile parameters 12 weeks after the end of treatment. It is apparent that successful eradication of $\mathrm{HCV}$ promotes normalization of the cellular function of hepatocytes improving hepatic lipid production. This highlights the strong association between HCV and lipid levels. A limitation associated with this finding is that the present study did not assess the diet, physical activity level, waist circumference, and family history of patients, which are crucial factors that influence lipid metabolism.

Notably, lipid profile components were found to be significantly lower in cirrhotic patients, a finding which is in accordance with several other studies that demonstrated similar results [19-22]. It is apparent that successful eradication of $\mathrm{HCV}$ promotes normalization of the cellular function of hepatocytes improving hepatic lipid production, reflecting the strong association and interaction between $\mathrm{HCV}$ and lipid levels. A limitation associated with this finding is that the present study did not assess the dietary habits, physical activity, waist circumference, and family history of patients, which are crucial factors that influence lipid metabolism.

On the other hand, the current study demonstrated a significant decrease in Lp-PLA2 concentration after DAA therapy in patients who experienced SVR, while patients who did not achieve SVR experienced a rise in Lp-PLA2, yet this increase was of no statistical significance. This finding is in accordance with a study conducted by Chew et al. [23]. It is a distinct finding that might be explained by the ongoing HCV viremia, which in turn augments hepatic inflammation, and promotes further systemic immune activation and inflammation.

As per the Framingham risk score, $70 \%$ of patients were defined as low risk, with only $30 \%$ classified as moderate/high risk at baseline. Furthermore, there was no significant difference in calculated risk scores and risk stratification into each group after treatment as compared to baseline, indicating a lack of any correlation between HCV clearance and this score.

Table 3 Comparison between pre-treatment and post-treatment lipid profile and Lp-PLA2 in patients who achieved SVR ( $n=86$ )

\begin{tabular}{|c|c|c|c|c|}
\hline \multirow[t]{2}{*}{ Lipid parameter } & \multicolumn{2}{|l|}{ Time } & \multicolumn{2}{|c|}{ Paired t-test } \\
\hline & Pre-treatment & 12 weeks post-treatment & $\mathrm{t}$ & $\mathrm{p}$ \\
\hline LDL (mg/dl) & $71.977 \pm 24.126(26-130)$ & $103.244 \pm 46.570(44-203)$ & -9.395 & $<0.001$ \\
\hline Total cholesterol (mg/dl) & $170 \pm 40.344(80-278)$ & $195.663 \pm 55.678(92-311)$ & -8.764 & $<0.001$ \\
\hline HDL (mg/dl) & $48.43 \pm 6.785(31-60)$ & $53.907 \pm 8.674(37-71)$ & -10.1 & $<0.001$ \\
\hline Lp-PLA2 (ng/ml) & $322.372 \pm 79.146(189-498)$ & $263.791 \pm 51.804(166-412)$ & 13.829 & $<0.001$ \\
\hline
\end{tabular}

Abbreviations: $n$, number; $L D L$, low-density lipoprotein; $H D L$, high-density lipoprotein; $L p-P L A 2$, lipoprotein-associated phospholipase $A 2$ 
Table 4 Comparison between pre-treatment and post-treatment lipid profile and Lp-PLA2 in patients who failed to achieve SVR $(n=4)$

\begin{tabular}{|c|c|c|c|c|}
\hline \multirow[t]{2}{*}{ Lipid parameter } & \multicolumn{2}{|l|}{ Time } & \multicolumn{2}{|c|}{ Paired t-test } \\
\hline & Pre-treatment & 12 weeks post-treatment & $\mathrm{t}$ & $\mathrm{p}$ \\
\hline LDL (mg/dl) & $33.75 \pm 4.573(27-37)$ & $36.5 \pm 4.655(30-41)$ & -2.200 & 0.115 \\
\hline Total cholesterol (mg/dl) & $114 \pm 32.527$ (87-158) & $117.5 \pm 28.361(88-153)$ & -1.000 & 0.391 \\
\hline $\mathrm{HDL}(\mathrm{mg} / \mathrm{dl})$ & $38.75 \pm 6.702(32-48)$ & $37.25 \pm 5.123(30-42)$ & 0.878 & 0.444 \\
\hline Lp-PLA2 (ng/ml) & $370 \pm 98.668(260-474)$ & $392.25 \pm 88.733(319-500)$ & -1.648 & 0.198 \\
\hline
\end{tabular}

Abbreviations: $n$, number; $L D L$, low-density lipoprotein; $H D L$, high-density lipoprotein; $L p-P L A 2$, lipoprotein-associated phospholipase $A 2$

On the contrary, using a cut-off value of $>235 \mathrm{ng} / \mathrm{ml}$ for Lp-PLA2 mass, $17.78 \%$ of patients were found to be low risk, with $82.2 \%$ of patients identified as high risk at baseline. A significant decline in the number of patients classified as high risk was observed after treatment with DAAs, from 82.2 to $60 \%$, with a consequent rise in the number of low-risk patients to $40 \%$ post-treatment ( $p=$ 0.002). Comparable results were demonstrated by Chew et al., who conducted a study comprising $54 \mathrm{HCV} / \mathrm{HIV}$ co-infected patients administered peginterferon (PEG)/ ribavirin (RBV) for 72 weeks. At baseline, there was no difference in CVD risk class by Lp-PLA2 level, whereas, after treatment, Lp-PLA2 levels decreased, although not statistically significantly, amongst SVRs (median change $=-17.5 \mathrm{ng} / \mathrm{ml}$ [IQR, -67.0 to 47.0$]$ ) but not non-SVRs (median change $=9.50 \mathrm{ng} / \mathrm{ml}[\mathrm{IQR},-49.0$ to 67.0$]$ ). There was a statistically significant difference in CVD risk class distribution by Lp-PLA2 level at 24 weeks after the end of treatment, with 25 of 27 (93\%) of the nonSVR group in the high-risk category compared with 17 of $27(63 \%)$ of the SVR group $(p=0.021)$ [23]. Another study conducted by Chew et al. aimed to predict CVD risk in $\mathrm{HCV}$-infected and $\mathrm{HCV}$ non-infected patients using the Framingham risk score. In unadjusted analyses, the Framingham risk score was similar between both groups $(p=0.192)$, while adjusting for CVD risk factors overlooked by the Framingham risk score (age, race, BMI, chronic kidney disease, drug and alcohol use, and HIV status), HCV infection was associated with minimally lower risk score $(p<0.001)$ [24]. This suggests that the Framingham risk score may underestimate CVD risk in these patients, which is in accordance with our study.

A lack of association of Lp-PLA2 with the degree of liver disease was evident in the present study as the difference in Lp-PLA2 concentration between cirrhotic and non-cirrhotic patients was statistically insignificant $(S=$ 0.463 ), suggesting that it may be less confounded by hepatic dysfunction as opposed to hepatically produced CVD biomarkers.

Lp-PLA2 concentration was found to show a significant positive correlation with age, smoking, BMI, hypertension, diabetes, FBG, and HbA1c level. Gender differences in Lp-PLA2 levels were also found; men had significantly higher levels than women $(358.018 \pm 77.133$ vs. $271.8 \pm 51.467 \mathrm{ng} / \mathrm{ml} ; p<0.001)$. Lower Lp-PLA2 levels in women could be explained by the fact that estrogen hormone causes down-regulation of Lp-PLA2 expression due to lower concentrations of LDL cholesterol in women or estrogen-related decrease in plateletactivating factor acetylhydrolase activity [25]. Of note,

Table 5 Relationship between baseline LP-PLA2 and gender, smoking, hypertension, diabetes, and ease of treatment

\begin{tabular}{|c|c|c|c|c|c|c|}
\hline \multirow[t]{2}{*}{ Parameter } & & \multirow[t]{2}{*}{ Lp-PLA2 (ng/ml) } & \multicolumn{4}{|c|}{ t-test or ANOVA } \\
\hline & & & $t$ or $F$ & $p$ & & \\
\hline \multirow[t]{2}{*}{ Gender } & Male $(n=55)$ & $358.018 \pm 77.133$ & 5.832 & $<0.001$ & & \\
\hline & Female $(n=35)$ & $271.8 \pm 51.467$ & & & & \\
\hline \multirow[t]{2}{*}{ Smoking } & Smoker $(n=18)$ & $444.833 \pm 26.425$ & 10.83 & $<0.001$ & & \\
\hline & Non-smoker $(n=72)$ & $294.403 \pm 57.237$ & & & & \\
\hline \multirow[t]{2}{*}{ Hypertension } & Hypertensive $(n=15)$ & $396.8 \pm 69.548$ & 4.17 & $<0.001$ & & \\
\hline & Normotensive $(n=75)$ & $310.027 \pm 74.298$ & & & & \\
\hline \multirow[t]{3}{*}{ Diabetes } & Diabetic $(n=7)$ & $398 \pm 51.095$ & 5.171 & $0.008+$ & $D \& P$ & $0.440^{\ddagger}$ \\
\hline & Pre-diabetic $(n=13)$ & $353.923 \pm 86.238$ & & & D\&N & $0.015^{\ddagger}$ \\
\hline & Non-diabetic $(n=70)$ & $311.671 \pm 76.597$ & & & P\&N & $0.167^{\ddagger}$ \\
\hline \multirow[t]{2}{*}{ Ease of treatment } & Easy to treat $(n=45)$ & $301.444 \pm 78.506$ & -2.837 & 0.006 & & \\
\hline & Difficult to treat $(n=45)$ & $347.533 \pm 75.582$ & & & & \\
\hline
\end{tabular}

†ANOVA (F) test, ${ }^{\ddagger}$ post hoc test

Abbreviations: $n$, number; $L p-P L A 2$, lipoprotein-associated phospholipase $A 2 ; D$, diabetic; $P$, pre-diabetic; $N$, non-diabetic 
Table 6 Correlation between Lp-PLA2 level and socio-clinical parameters, Framingham risk score (2008), and liver stiffness score at baseline and at 12 weeks post-treatment

\begin{tabular}{|c|c|c|c|c|}
\hline \multirow[t]{3}{*}{ Studied parameter } & \multicolumn{4}{|c|}{ Lp-PLA2 (ng/ml) } \\
\hline & \multicolumn{2}{|c|}{ Pre-treatment correlations } & \multicolumn{2}{|c|}{ Post-treatment correlations } \\
\hline & $\bar{r}$ & $\mathrm{p}$ & $\mathbf{R}$ & $\mathrm{p}$ \\
\hline Age & 0.350 & 0.001 & 0.409 & $<0.001$ \\
\hline BMI $\left(\mathrm{kg} / \mathrm{m}^{2}\right)$ & 0.331 & 0.001 & 0.258 & 0.014 \\
\hline FBG (mg/dl) & 0.353 & 0.001 & 0.412 & $<0.001$ \\
\hline $\mathrm{HbA1c}$ & 0.332 & 0.001 & 0.403 & $<0.001$ \\
\hline Platelets $\left(10^{3} / \mathrm{l}\right)$ & -0.225 & 0.033 & -0.229 & 0.03 \\
\hline AST (IU/I) & 0.188 & 0.076 & 0.296 & 0.005 \\
\hline ALT (IU/I) & 0.099 & 0.355 & 0.033 & 0.76 \\
\hline Albumin (g/dl) & -0.336 & 0.001 & -0.31 & 0.003 \\
\hline LDL (mg/dl) & 0.142 & 0.182 & 0.197 & 0.062 \\
\hline Total cholesterol (mg/dl) & 0.077 & 0.468 & 0.043 & 0.689 \\
\hline $\mathrm{HDL}(\mathrm{mg} / \mathrm{dl})$ & -0.096 & 0.366 & -0.284 & 0.007 \\
\hline Framingham score & 0.669 & $<0.001$ & 0.677 & $<0.001$ \\
\hline Liver stiffness score $(\mathrm{kPa})$ & 0.157 & 0.139 & 0.276 & 0.008 \\
\hline
\end{tabular}

Abbreviations: $L p$-PLA2, lipoprotein-associated phospholipase A2; BMI, body mass index; FBG, fasting blood glucose; HbA1c, hemoglobin A1c; $A S T$, aspartate transaminase; $A L T$, alanine transaminase; $L D L$, low-density lipoprotein; $H D L$, high-density lipoprotein

estrogen replacement therapy could significantly reduce Lp-PLA2 activity in healthy post-menopausal women [26], while administration of steroids with progesterone-like activity increases Lp-PLA2 activity [27]. Additionally, smoking may increase the carrier (LDL) and the substrate (oxidized LDL) for Lp-PLA2 [28].

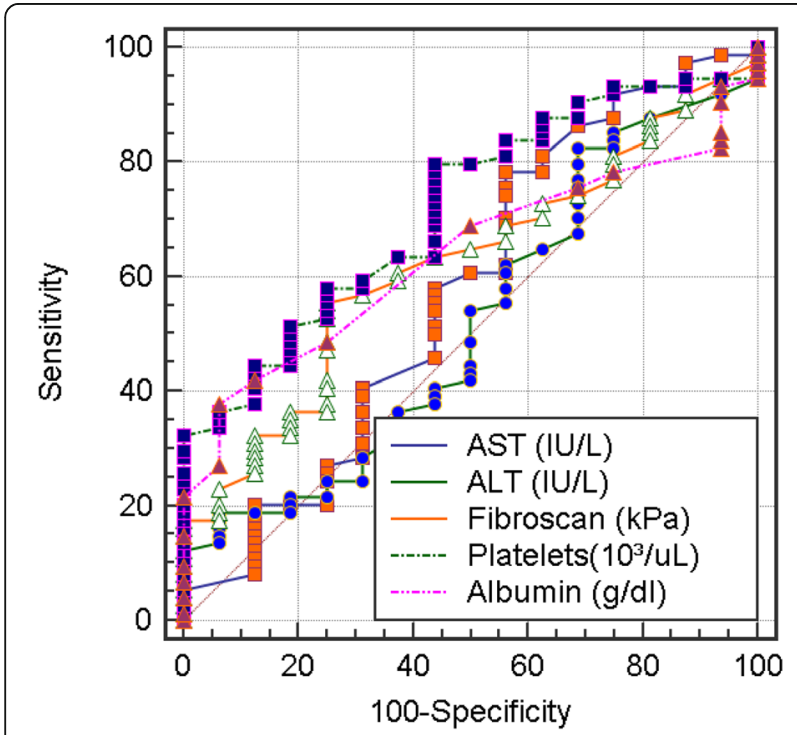

Fig. 1 ROC curve of the best cut-off value of baseline AST, ALT, liver stiffness score, platelet count, and serum albumin in discriminating high CVD risk (Lp-PLA2 > $235 \mathrm{ng} / \mathrm{ml}$ ) from low CVD risk (LpPLA2 $\leq 235 \mathrm{ng} / \mathrm{ml}$ ). Abbreviations: AST, aspartate transaminase; $A L T$, alanine transaminase; ROC, receiver operating characteristic; CVD, cardiovascular disease; Lp-PLA2, lipoprotein-associated phospholipase A2
Finally, our study demonstrates the diagnostic performance of the best cut-off values of baseline AST, ALT, serum albumin, platelet count, and liver stiffness score in the prediction of cardiovascular disease risk in chronic HCV-infected patients. A cut-off value of $>28$ IU/l for ALT yielded the highest sensitivity (82.43\%) in predicting CVD risk, while an albumin level $\leq 3.7 \mathrm{~g} / \mathrm{dl}$ was most specific (93.75\%) with the highest positive predictive value (96.6\%).

We have to declare that the interpretation of the favorable changes in Lp-PLA2 mass was hindered by the lack of validation of the biomarker for CVD risk prediction in the context of $\mathrm{HCV}$ infection and the inability to correlate biomarker levels with hard outcomes such as CVD events or valid alternative means. Despite these limitations, our data remain informative, and further investigation that aims to test the predictive utility of both non-hepatic and hepatic CVD biomarkers and quantifying the potential benefit of HCV treatment on CVD is warranted.

\section{Conclusion}

Traditional risk score calculators incorporating hepatically produced biomarkers, such as Framingham risk score, may underestimate CVD risk in $\mathrm{HCV}$-infected patients, while Lp-PLA2 may provide a better estimate of CVD risk as it is a non-hepatically produced biomarker with no relation to liver disease severity. Furthermore, HCV clearance may reduce CVD risk as perpetuated by the significant reduction in Lp-PLA2 levels after DAA therapy and SVR. 


\section{Abbreviations}

AFP: Alpha-fetoprotein; ALT: Alanine transaminase; ANOVA: Analysis of variance; AST: Aspartate transaminase; CBC: Complete blood count; CVD: Cardiovascular disease; DCV: Daclatasvir; DM: Diabetes mellitus; ELISA: Enzyme-linked immunosorbent assay; FBG: Fasting blood glucose; HbA1c: Hemoglobin A1c; HBsAg: Hepatitis B surface antigen; HBV: Hepatitis B virus; HCC: Hepatocellular carcinoma; HCV: Hepatitis C virus; HIV: Human immunodeficiency virus; HRP: Horseradish peroxidase; hsCRP: High-sensitivity C-reactive protein; INR: International normalized ratio; IQR: Interquartile range; IR: Insulin resistance; LDL: Low-density lipoprotein; Lp-PLA2: Lipoproteinassociated phospholipase A2; NCCVH: National Committee for Control of Viral Hepatitis; PEG: Peginterferon; RBV: Ribavirin; RNA: Ribonucleic acid; ROC: Receiver operator characteristic; SD: Standard deviation; SOF: Sofosbuvir; SVR: Sustained virologic response; TMB: Tetramethylbenzidine

\section{Acknowledgements}

The authors express their gratitude to the staff members of the Clinical Pathology and Internal Medicine (gastroenterology and hepatology unit) departments at Ain Shams University Hospital, Cairo, Egypt.

\section{Authors' contributions}

Al proposed the research subject, conducted a final revision of the gathered data, and shared in writing the manuscript. BE shared in the data acquisition and revision and drafting of the manuscript, besides being the corresponding author. KE made a substantial contribution in writing the manuscript and revising it critically for important intellectual content. RSM contributed to the study by revising and drafting the work and participated in writing the manuscript. SAl revised the laboratory analysis, tabulated the data, and helped in the statistical analysisS of the collected data. ES shared in the data collection, revision, and interpretation of the statistical analysis of all data and in writing the manuscript. All authors have read and approved the submitted version of the manuscript. Each author agreed to be personally accountable for their own contributions and ensured that questions related to the accuracy or integrity of any part of the work are appropriately investigated and resolved.

\section{Funding}

This research did not receive any specific grant from any funding agencies.

\section{Availability of data and materials}

The datasets used and analyzed during the current study are available from the corresponding author on reasonable request.

\section{Declarations}

\section{Ethics approval and consent to participate}

The study was performed according to the ethical standards for human experimentation and in accordance with the ethical principles of the 1975 Declaration of Helsinki. Patients included in the study signed an informed written consent to participate. All procedures performed in this study were in accordance with the standards of the Research Ethics Committee (REC) of the Faculty of Medicine, Ain Shams University (FWA 000017585).

\section{Consent for publication}

Not applicable.

\section{Competing interests}

The authors declare that they have no competing interests.

\section{Author details}

'Department of Internal Medicine, Gastroenterology and Hepatology Unit, Faculty of Medicine, Ain Shams University, Cairo 11566, Egypt. ${ }^{2}$ Department of Clinical Pathology, Faculty of Medicine, Ain Shams University, Cairo 11566, Egypt.
Received: 7 April 2021 Accepted: 18 May 2021

Published online: 26 May 2021

\section{References}

1. Negro F (2014) Facts and fictions of HCV and comorbidities: steatosis, diabetes mellitus, and cardiovascular diseases. J Hepatol. 61 (1):S69-S78. https://doi.org/10.1016/j.jhep.2014.08.003

2. Kralj D, Virović Jukić L, Stojsavljević S, Duvnjak M, Smolić M, Čurčić IB (2016) Hepatitis C virus, insulin resistance, and steatosis. J Clin Transl Hepatol 4(1): 66-75. https://doi.org/10.14218/JCTH.2015.00051

3. El Sagheer G, Soliman E, Ahmad A, Hamdy L (2018) Study of changes in lipid profile and insulin resistance in Egyptian patients with chronic hepatitis C genotype 4 in the era of DAAs. Libyan J Med. 13(1):1435124. https://doi.org/10.1080/19932820.2018.1435124

4. Kohli A, Shaffer A, Sherman A, Kottilil S (2014) Treatment of hepatitis C: a systematic review. JAMA. 312(6):631-640. https://doi.org/10.1001/ja ma.2014.7085

5. Meissner EG, Lee YJ, Osinusi A, Sims Z, Qin J, Sturdevant D, McHutchison J, Subramanian M, Sampson M, Naggie S, Patel K, Remaley AT, Masur H, Kottilil $S$ (2015) Effect of sofosbuvir and ribavirin treatment on peripheral and hepatic lipid metabolism in chronic hepatitis C virus, genotype 1-infected patients. Hepatology. 61(3):790-801. https://doi.org/10.1002/hep.27424

6. Corey KE, Kane E, Munroe C, Barlow LL, Zheng H, Chung RT (2009) Hepatitis $\mathrm{C}$ virus infection and its clearance alter circulating lipids: implications for long-term follow-up. Hepatology. 50(4):1030-1037. https://doi.org/10.1002/ hep.23219

7. Dhingra R, Vasan RS (2017) Biomarkers in cardiovascular disease: statistical assessment and section on key novel heart failure biomarkers. Trends Cardiovasc Med. 27(2):123-133. https://doi.org/10.1016/j.tcm.2016.07.005

8. Bhatti S, Hakeem A, Cilingiroglu M (2010) Lp-PLA(2) as a marker of cardiovascular diseases. Curr Atheroscler Rep. 12(2):140-144. https://doi. org/10.1007/s11883-010-0095-6

9. Lavi S, McConnell JP, Rihal CS et al (2007) Local production of lipoproteinassociated phospholipase A2 and lysophosphatidylcholine in the coronary circulation: association with early coronary atherosclerosis and endothelial dysfunction in humans. Circulation. 115(21):2715-2721. https://doi.org/10.11 61/CIRCULATIONAHA.106.671420

10. Cojocaru M, Cojocaru IM, Silosi I (2010) Lipoprotein-associated phospholipase A2 as a predictive biomarker of sub-clinical inflammation in cardiovascular diseases. Maedica (Bucur). 5(1):51-55

11. Lanman RB, Wolfert RL, Fleming JK, Jaffe AS, Roberts WL, Warnick GR, McConnell JP (2006) Lipoprotein-associated phospholipase A2: review and recommendation of a clinical cut point for adults. Prev Cardiol. 9(3):138143. https://doi.org/10.1111/j.1520-037x.2006.05547.x

12. Elsharkawy A, Fouad R, El Akel W et al (2017) Sofosbuvir-based treatment regimens: real life results of 14409 chronic HCV genotype 4 patients in Egypt. Aliment Pharmacol Ther. 45(5):681-687. https://doi.org/10.1111/a pt.13923

13. El-Akel W, El-Sayed MH, El Kassas M et al (2017) National treatment programme of hepatitis C in Egypt: hepatitis C virus model of care. S. 24(4): 262-267. https://doi.org/10.1111/jvh.12668

14. D'Agostino RB Sr, Vasan RS, Pencina MJ, Wolf PA, Cobain M, Massaro JM, Kannel WB (2008) General cardiovascular risk profile for use in primary care: the Framingham Heart Study. Circulation. 117(6):743-753. https://doi.org/1 0.1161/CIRCULATIONAHA.107.699579

15. Babiker A, Jeudy J, Kligerman S, Khambaty M, Shah A, Bagchi S (2017) Risk of cardiovascular disease due to chronic hepatitis $C$ infection: a review. J Clin Transl Hepatol. 5(4):343-362. https://doi.org/10.14218/JCTH.2017.00021

16. Butt AA, Yan P, Simon TG, Chung RT, Abou-Samra AB, ERCHIVES study team (2015) Changes in circulating lipids level over time after acquiring HCV infection: results from ERCHIVES. BMC Infect Dis 15(1):510. https://doi.org/1 $0.1186 / 512879-015-1268-2$

17. Ali M, Madjid M (2009) Lipoprotein-associated phospholipase A2: a cardiovascular risk predictor and a potential therapeutic target. Future Cardiol. 5(2):159-173. https://doi.org/10.2217/14796678.5.2.159

18. Zalewski A, Macphee C (2005) Role of lipoprotein-associated phospholipase A2 in atherosclerosis: biology, epidemiology, and possible therapeutic target. Arterioscler Thromb Vasc Biol. 25(5):923-931. https://doi.org/10.1161/ 01.ATV.0000160551.21962.a7

19. Kuo YH, Chuang TW, Hung CH, Chen CH, Wang JH, Hu TH, Lu SN, Lee CM (2011) Reversal of hypolipidemia in chronic hepatitis $C$ patients after 
successful antiviral therapy. J Formos Med Assoc. 110(6):363-371. https://doi. org/10.1016/S0929-6646(11)60054-5

20. Nagano T, Seki N, Tomita Y, Sugita T, Aida Y, Itagaki M, Sutoh S, Abe H, Tsubota A, Aizawa Y (2015) Impact of chronic hepatitis C virus genotype 1b infection on triglyceride concentration in serum lipoprotein fractions. Int J Mol Sci 16(9):20576-20594. https://doi.org/10.3390/ijms160920576

21. Dai CY, Chuang WL, Ho CK, Hsieh MY, Huang JF, Lee LP, Hou NJ, Lin ZY, Chen SC, Hsieh MY, Wang LY, Tsai JF, Chang WY, Yu ML (2008) Associations between hepatitis $C$ viremia and low serum triglyceride and cholesterol levels: a community-based study. J Hepatol. 49(1):9-16. https://doi.org/10.1 016/j.jhep.2008.03.016

22. Jang ES, Won JE, Jung Jl, Lee SH, Kim JW, Jeong SH (2011) The effect of antiviral therapy on serum cholesterol levels in chronic hepatitis C. Gut Liver. 5(3):356-362. https://doi.org/10.5009/gnl.2011.5.3.356

23. Chew KW, Hua L, Bhattacharya D et al (2014) The effect of hepatitis $C$ virologic clearance on cardiovascular disease biomarkers in human immunodeficiency virus/hepatitis C virus coinfection. Open Forum Infect Dis 1(3):ofu104. https://doi.org/10.1093/ofid/ofu104

24. Chew KW, Bhattacharya D, McGinnis KA et al (2015) Short communication: Coronary heart disease risk by Framingham Risk Score in hepatitis $C$ and HIV/hepatitis C-coinfected persons. AIDS Res Hum Retroviruses. 31(7):718722. https://doi.org/10.1089/AID.2014.0284

25. Miyaura S, Maki N, Byrd W, Johnston JM (1991) The hormonal regulation of platelet-activating factor acetylhydrolase activity in plasma. Lipids. 26(12): 1015-1020. https://doi.org/10.1007/BF02536494

26. Yoshimura T, Ohshige A, Maeda T, Ito M, Okamura H (1999) Estrogen replacement therapy decreases platelet-activating factor-acetylhydrolase activity in post-menopausal women. Maturitas. 31(3):249-253. https://doi. org/10.1016/s0378-5122(99)00004-3

27. Ohshige A, Ito M, Koyama H, Maeda T, Yoshimura T, Okamura H (1994) Effects of estrogen and progesterone on platelet-activating factor acetylhydrolase activity in ovariectomised rats. Artery. 21(4):234-242

28. Yanbaeva DG, Dentener MA, Creutzberg EC, Wesseling G, Wouters EF (2007) Systemic effects of smoking. Chest. 131(5):1557-1566. https://doi.org/10.13 78/chest.06-2179

\section{Publisher's Note}

Springer Nature remains neutral with regard to jurisdictional claims in published maps and institutional affiliations.

\section{Submit your manuscript to a SpringerOpen ${ }^{\circ}$ journal and benefit from:}

- Convenient online submission

- Rigorous peer review

- Open access: articles freely available online

High visibility within the field

- Retaining the copyright to your article

Submit your next manuscript at $\boldsymbol{\nabla}$ springeropen.com 